\title{
Clinical manifestations and acid alpha-glucosidase mutation characterisation of a cohort of patients with late-onset Pompe disease in eastern China
}

\author{
Hui-Hui Zhao $^{1 \# \wedge}$, Zhi Ma ${ }^{1 \#}$, Zi-Xuan Ying ${ }^{1}$, Feng-Nan Niu ${ }^{2}$, Mao-Tao Luo ${ }^{1}$, Zheng Wang ${ }^{1}$, Xi Cheng ${ }^{1}$, \\ Qian-Qian Zhang ${ }^{1}$, Qi Niu ${ }^{1 \wedge}$ \\ ${ }^{1}$ Department of Geriatrics, The First Affiliated Hospital of Nanjing Medical University, Nanjing Medical University, Nanjing, China; ${ }^{2}$ Department \\ of Pathology, Nanjing Drum Tower Hospital, Nanjing Medical University, Nanjing, China \\ Contributions: (I) Conception and design: HH Zhao, X Cheng, Q Niu; (II) Administrative support: X Cheng, Q Niu; (III) Provision of study materials \\ or patients: HH Zhao, Z Ma, FN Niu, Q Niu; (IV) Collection and assembly of data: HH Zhao, Z Ma; (V) Data analysis and interpretation: HH \\ Zhao, Z Ma; (VI) Manuscript writing: All authors; (VII) Final approval of manuscript: All authors. \\ \#These authors contributed equally to this work. \\ Correspondence to: Qi Niu; Xi Cheng. Department of Geriatrics, The First Affiliated Hospital of Nanjing Medical University, Nanjing Medical \\ University, Nanjing 210029, China. Email: md_new@sina.com; chengxi_nanjing@163.com.
}

Background: Pompe disease is a rare, progressive, and life-threatening autosomal recessive disorder. In its late-onset form, the disease is primarily characterised by mild progressive proximal limb and respiratory muscle weakness. Mutations in the acid alpha-glucosidase $(G A A)$ gene cause lysosomal enzyme GAA to be significantly reduced or missing altogether, for which supplementation can be given through enzyme replacement therapy.

Methods: Fourteen patients diagnosed with late-onset Pompe disease (LOPD) in the First Affiliated Hospital of Nanjing Medical University from 2017 to 2021 were enrolled. GAA activity was measured based on enzymatic activity in dried blood spots, and next-generation sequencing was used to detect mutations in the GAA gene. The impacts of novel missense variants were determined by five different prediction algorithms. The structural figures of novel variants and their wide types were processed with PyMOL.

Results: The study included 14 patients with LOPD (male-to-female ratio, 1:1) from eastern China. The median age at symptom onset and diagnosis was 15.0 years (7-36 years) and 21.5 years (8-47 years), respectively. The median diagnostic delay from onset was 3.0 years ( $0-22$ years). Proximal muscle weakness was the first prominent symptom in 8 patients, while the other 6 patients experienced respiratory failure, chest congestion and asthma, and scoliosis. The most frequent mutation of the GAA gene was c.2238G $>C$ (p.W746C), which was observed at an allele frequency of $14.3 \%(4 / 28)$ and in $28.6 \%$ of patients (4/14). Four novel variants potentially related to the pathogenicity of LOPD were found: c.1299G>C (p.Q433H), c.1409A>G (p.N470S), c.2242delG (p.E748Rfs*16), and c.2832delA (p.E945Sfs*78).

Conclusions: The c.2238G $>\mathrm{C}$ (p.W746C) mutation was the most common mutation in 14 patients with LOPD from eastern China. This study has identified four novel variants in patients with LOPD. Predicting the pathogenicity of these novel variants may increase the understanding of the genetic mutation spectrum in LOPD. Our findings may also improve recognition of the characteristics of Chinese patients with LOPD.

Keywords: Late-onset Pompe disease (LOPD); glycogen storage disease type II (GSD II); acid alpha-glucosidase (GAA); GAA mutation; next-generation sequencing

Submitted Aug 08, 2021. Accepted for publication Dec 09, 2021.

doi: $10.21037 /$ atm-21-3710

View this article at: https://dx.doi.org/10.21037/atm-21-3710

^ ORCID: Hui-Hui Zhao, 0000-0003-3229-6232; Qi Niu, 0000-0001-9237-9553. 


\section{Introduction}

Pompe disease [glycogen storage disease type II (GSD II)] is a rare, progressive, and life-threatening autosomal recessive disorder caused by the lysosomal enzyme acid alpha-glucosidase (GAA) being significantly reduced or missing (1). Depending on their age at symptom onset, patients are typically classified as infantile-onset Pompe disease (IOPD) or late-onset Pompe disease (LOPD) $(2,3)$.

In its infantile-onset form, which is characterised by predominant and severe cardiomyopathy, the disease has a high mortality rate. The symptoms of LOPD are less severe than those of IOPD, and mainly include progressive proximal limb and respiratory muscle weakness, with cardiomyopathy being uncommon (4). Due to its nonspecific symptoms, LOPD is difficult to differentiate from other neuromuscular diseases. Muscle biopsy can detect glycogen deposition by periodic acid-Schiff staining. Decreased GAA activity in lymphocytes and GAA gene mutations are also important for the diagnosis of LOPD.

The GAA gene is located on chromosome 17q25.2-25.3 and contains 20 exons (5). As of August 2021, almost 900 different variants had been listed in the Pompe Disease Mutation Database. These gene mutations exhibit race specificity. In Caucasian and Belgian patients, for example, the most common mutation is c. $-32-13 \mathrm{~T}>\mathrm{G}(6)$, whereas c. $1935 \mathrm{C}>\mathrm{A}$ (p.D645E) and c.2238G>C (p.W746C) frequently appear in Taiwanese patients (7). However, despite the increasing awareness of Pompe disease, data on LOPD in patients from mainland China are still limited.

In this study, the clinical features of 14 mainland Chinese patients with LOPD were examined, and genetic analysis was performed. The following article is presented in accordance with the Materials Design Analysis Reporting (MDAR) reporting checklist (available at https://dx.doi. org/10.21037/atm-21-3710).

\section{Methods}

\section{Patients}

This study included 14 patients (Table 1) who were diagnosed with LOPD in the First Affiliated Hospital of Nanjing Medical University between 2017 and 2021. The study was conducted in accordance with the Declaration of Helsinki (as revised in 2013). The study was approved by the Medical Ethics Review Board of The First Affiliated Hospital of Nanjing Medical University (2021-SR-415). The patients and their families gave informed consent for the use of their medical data for research purposes.

Medical records of clinical manifestations and laboratory results were available for all confirmed cases. According to Chinese diagnostic guidelines, diagnoses were confirmed based on clinical features, reduced GAA enzymatic activity, and mutations in the $G A A$ gene. Dualenergy $\mathrm{X}$-ray absorptiometry was used to test bone mineral density, and whole-spine radiographs were performed to check for scoliosis. Respiratory conditions were assessed by pulmonary function test; however, some patients were unable to cooperate with the pulmonary function test due to their extremely poor respiratory function.

\section{Measurements of GAA enzymatic activity}

The NeoLSD MSMS kit (Perkin Elmer, USA) was used for quantitative measurement of GAA enzymatic activity in dried blood spots. A 3.2-mm (1/8 inch) dried blood spot was incubated in buffer solution containing the internal standard and substrate supplied with the kit, at $37^{\circ} \mathrm{C}$ for 18.5 hours. Following this, water and the NeoLSD extraction solution were added for extraction. Fifty microliters of supernatant was transferred to a new well and dried with nitrogen. One hundred microliters of flow solvent was added to the well before the experiment was run on the Waters UPLC/Xevo TQD tandem mass spectrometer. Data were obtained by using the multiple reaction monitoring mode of the tandem mass spectrometry system. Enzymatic activity was measured according to the signal response of the target analyte relative to the internal standard, and was expressed as $\mu \mathrm{mol} / \mathrm{L} / \mathrm{h}$. The reference range for GAA enzymatic activity is $1.46-$ $20.34 \mu \mathrm{mol} / \mathrm{L} / \mathrm{h}$.

\section{Next-generation sequencing of the $G A A$ gene}

Genomic DNA was extracted from peripheral blood samples of 14 patients using the CWE9600 Blood DNA Kit (CW2531, CWBio, Beijing, China). The GAA genes were amplified using specific primers. Following this, the DNA concentrations were determined using the Qubit dsDNA HS Assay Kit (Q32851, Invitrogen, Carlsbda, CA, USA) with a Qubit fluorometer (Q33216, Invitrogen). Quality control was carried out through agarose gel (1\%) electrophoresis. Finally, $1 \mu \mathrm{g}$ of amplified DNA per sample was collected for the generation of a sequencing library. Quantified DNA samples were sheared into 200-300 bp fragments. The KAPA Library Preparation Kit (KK8234, Kapa Biosystems, Boston, MA, USA) was used to prepare 
Table 1 Clinical manifestation and genetic analysis of 14 Chinese patients with late-onset Pompe disease

\begin{tabular}{|c|c|c|c|c|c|c|c|c|c|}
\hline No. & Gender & Initial symptoms & \multicolumn{2}{|c|}{ Age (years) } & CK (U/L) & $\begin{array}{l}\text { GAA activity } \\
(\mu \mathrm{mol} / \mathrm{L} / \mathrm{h})\end{array}$ & \multicolumn{2}{|c|}{ Nucleotide change } & $\begin{array}{c}\text { Requirement } \\
\text { of ventilator } \\
\text { support }\end{array}$ \\
\hline 2 & M & $\begin{array}{l}\text { Airway infections, } \\
\text { respiratory failure }\end{array}$ & 36 & 36 & 300 & 0.30 & c. $1409 A>G^{\#}$ & c. $1409 A>G^{\#}$ & Yes \\
\hline 4 & M & Muscle weakness of limbs & 11 & 16 & 2,336 & - & c. $784 \mathrm{G}>\mathrm{A}$ & c. $2297 A>G$ & No \\
\hline 5 & $\mathrm{~F}$ & Muscle weakness of limbs & 8 & 8 & 1,969 & 0.18 & c. $1129 \mathrm{G}>\mathrm{A}$ & c.2154delC & Yes \\
\hline 6 & $\mathrm{~F}$ & Muscle weakness of limbs & 12 & 23 & 387 & 0.16 & c.1320_1322delGAT & c. $2238 \mathrm{G}>\mathrm{C}$ & Yes \\
\hline 7 & $\mathrm{~F}$ & Muscle weakness of limbs & 16 & 23 & 837 & 0.00 & c. $1409 A>G^{\#}$ & c. $2161 \mathrm{G}>\mathrm{T}$ & Yes \\
\hline 10 & M & Muscle weakness of limbs & 12 & 18 & 950 & 0.20 & c. $2237 \mathrm{G}>\mathrm{A}$ & c. $2238 \mathrm{G}>\mathrm{C}$ & No \\
\hline 11 & M & $\begin{array}{l}\text { Airway infections, } \\
\text { respiratory failure }\end{array}$ & 14 & 31 & 1,018 & 0.13 & c. $1299 \mathrm{G}>\mathrm{C}^{\#}$ & c.2832delA $\mathrm{A}^{\#}$ & Yes \\
\hline 12 & M & Scoliosis & 14 & 15 & 660 & 0.14 & c. $1299 \mathrm{G}>\mathrm{C}^{\#}$ & c.2832delA ${ }^{\#}$ & No \\
\hline 13 & $\mathrm{~F}$ & $\begin{array}{l}\text { Airway infections, } \\
\text { respiratory failure }\end{array}$ & 27 & 27 & 556 & 0.25 & c.1879_1881delTCC & c. $2297 A>G$ & Yes \\
\hline 14 & $\mathrm{~F}$ & Muscle weakness of limbs & 39 & 47 & 229 & 0.36 & c. $1634 \mathrm{C}>\mathrm{T}$ & c.2426delC & No \\
\hline
\end{tabular}

The reference range for GAA enzyme activity is 1.46-20.34 $\mu \mathrm{mol} / \mathrm{L} / \mathrm{h}$. \#, the novel variants. CK, creatine kinase; GAA, acid alphaglucosidase; M, male; F, female.

DNA libraries in adherence with the manufacturer's instructions. The constructed libraries were sequenced on the Illumina HiSeq X10 platform (Illumina, San Diego, USA) using a 150-bp paired-end reads protocol.

The raw data (stored in the FASTQ format) obtained from HiSeq X10 was subjected to quality control and aligned to the human reference genome sequence hg19 (http://genome.ucsc.edu/) using Burrows-Wheeler Aligner (http://bio-bwa.sourceforge.net/). The GATK (Genome Analysis ToolKit) software (http://www.broadinstitute.org/ gatk) was used to call single-nucleotide polymorphisms. The called variants were annotated using several public databases including 1000 Genomes Project, ExAC, gnomAD, ESP6500, CCDS, RefSeq, and Ensembl. Annotation content included the variant position, variant type, allele frequency, and conservation prediction would help to locate mutations related to LOPD.

All $G A A$ variants discovered by next-generation sequencing were confirmed by Sanger sequencing using specific primers. Twenty micromoles of quantified DNA was added into the polymerase chain reaction (PCR) mixture, which contained $12.5 \mu \mathrm{L} 2 \times$ Phanta Max Buffer, $0.5 \mu \mathrm{L}$ Phanta Max SuperFidelity DNA Polymerase $(1 \mathrm{U} / \mu \mathrm{L}), 0.5 \mu \mathrm{L}$ dNTP Mix (10 $\mathrm{mM}$ each), $1 \mu \mathrm{L}$ forward primers, $1 \mu \mathrm{L}$ reverse primers, and water, to a final volume of $25 \mu \mathrm{L}$. The following protocol was used for amplification: denaturation at $95{ }^{\circ} \mathrm{C}$ for 5 minutes, followed by 25 cycles $\left(95^{\circ} \mathrm{C}\right.$ for 30 seconds, $65^{\circ} \mathrm{C}$ for 30 seconds, decreasing by $0.6^{\circ} \mathrm{C}$ per cycle, and then $72{ }^{\circ} \mathrm{C}$ for 30 seconds) and 20 cycles $\left(95^{\circ} \mathrm{C}\right.$ for 30 seconds, $50{ }^{\circ} \mathrm{C}$ for 30 seconds, and then $72{ }^{\circ} \mathrm{C}$ for 30 seconds), and then $72{ }^{\circ} \mathrm{C}$ for 10 minutes as a final elongation step. Pedigree verification was also used to confirm the variants detected in the patients.

\section{Results}

\section{Clinical symptoms of the patients}

The 14 patients came from eastern China and included two brothers (No. 11 and 12) from the same family. Table 1 


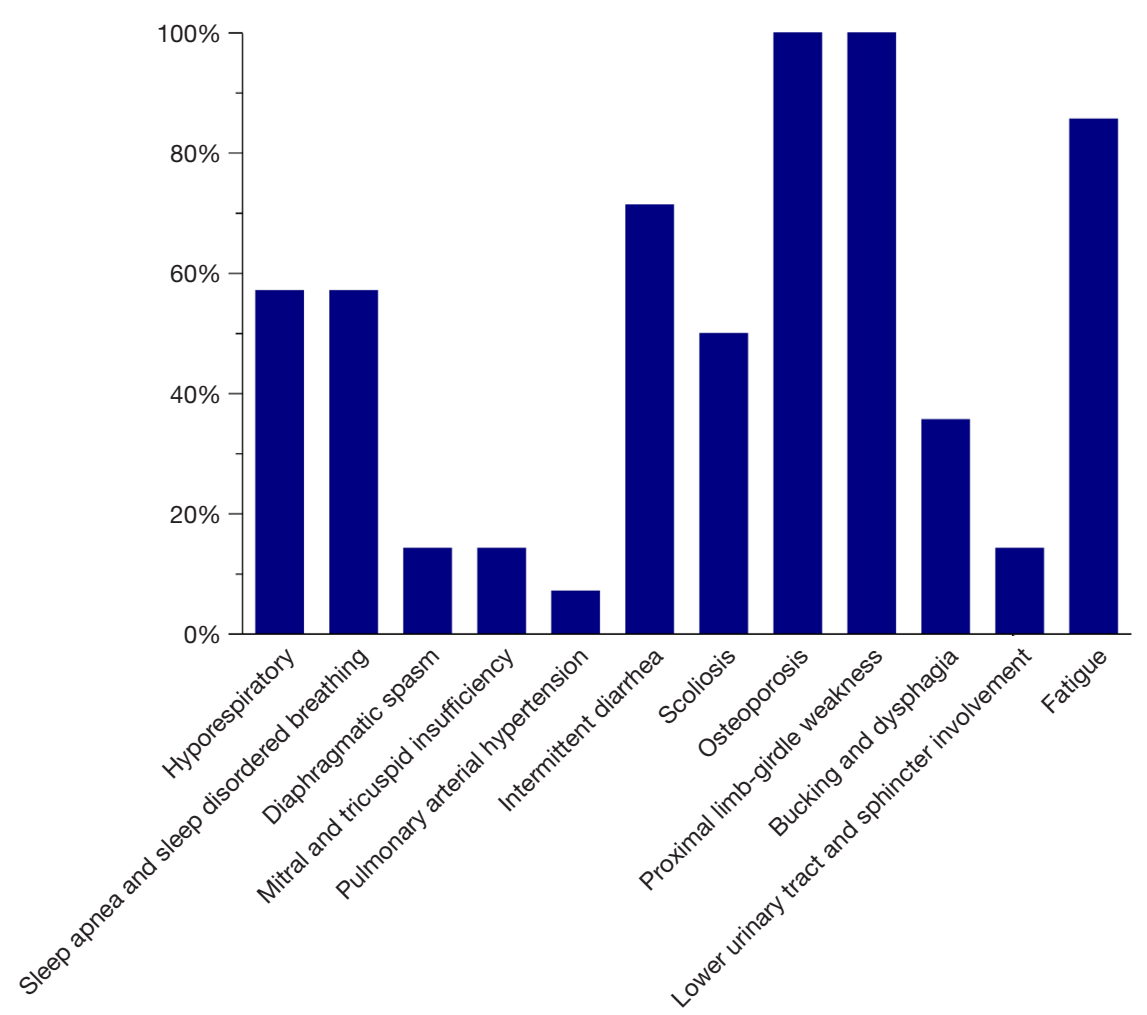

Figure 1 Clinical manifestations of patients with $G A A$ mutations. All the patients presented with limb-gird muscle weakness and osteoporosis. Other common symptoms included fatigue $(85.71 \%, 12 / 14)$ and gastrointestinal dysfunction with intermittent diarrhoea (71.43\%, 10/14). The occurrence rates of dyspnoea, sleep apnoea and sleep-disordered breathing, and diaphragmatic spasm were $57.14 \%$ (8/14), 57.14\% (8/14), and 14.29\% (2/14), respectively. Two patients (14.29\%, 2/14) had mild mitral and tricuspid insufficiency, including one $(7.14 \%, 1 / 14)$ with extrapulmonary arterial hypertension. Half of the patients $(50.00 \%, 7 / 14)$ had scoliosis of different degrees, for which two patients underwent posterior spinal correction surgery. Also, five patients had bucking and dysphagia, and two patients had lower urinary tract and sphincter involvement. The chart shows the proportion of the patients with each manifestation. The $y$-axis showed the proportion of each clinical features. GAA, acid alpha-glucosidase.

summarises the clinical manifestations of the 14 patients. The male-to-female ratio was $1: 1$. The median ages at symptom onset and diagnosis were 15.0 years ( $7-36$ years) and 21.5 years ( $8-47$ years), respectively. The median diagnostic delay from onset was 3.0 years ( $0-22$ years).

Eight patients $(57.1 \%, 8 / 14)$ displayed a progressive limb weakness as an initial symptom. For three patients $(21.4 \%$, $3 / 14$ ), airway infection with respiratory failure was the first symptom. Two patients (No. 3 and 12) presented with scoliosis as the first symptom and subsequently underwent surgery. One patient's initial symptoms included chest congestion and onset of asthma.

Although the patients in the cohort presented without hypertrophic cardiomyopathy, patients 1 and 13 exhibited mild mitral and tricuspid insufficiency; further, patient 13 displayed extrapulmonary arterial hypertension. Figure 1 and Table 2 show the clinical features of the patients. All patients had different degrees of limb-gird muscle weakness and osteoporosis during the course of disease progression. A large proportion of the patients $(71.43 \%, 10 / 14)$ had gastrointestinal dysfunction and presented with intermittent diarrhoea. Due to respiratory muscle (diaphragm and chest wall) and laryngopharyngeal muscle weakness, some patients demonstrated dyspnoea $(57.14 \%, 8 / 14)$, sleep apnoea and sleep-disordered breathing $(57.14 \%, 8 / 14)$, bucking and dysphagia $(35.71 \%, 5 / 14)$, and diaphragmatic spasm $(14.29 \%, 2 / 14)$. None of our cohort had cognitive impairment.

GAA activity was detected in 13 patients, and the mean level was $0.20 \mu \mathrm{mol} / \mathrm{L} / \mathrm{h}(0-0.36 \mu \mathrm{mol} / \mathrm{L} / \mathrm{h})$. Two patients (No. 4 and 7) received non-regular and insufficient amounts of enzyme replacement therapy (ERT); recent 
Table 2 Clinical manifestation of patients with $G A A$ mutations

\begin{tabular}{|c|c|c|c|c|c|c|c|c|c|c|c|c|c|c|}
\hline Clinical manifestation & 1 & 2 & 3 & 4 & 5 & 6 & 7 & 8 & 9 & 10 & 11 & 12 & 13 & 14 \\
\hline Dyspnea & & + & & & + & + & + & + & + & & + & & + & \\
\hline $\begin{array}{l}\text { Sleep apnea and sleep } \\
\text { disordered breathing }\end{array}$ & & + & & & + & + & + & + & + & & + & & + & \\
\hline Mitral and tricuspid insufficiency & + & & & & & & & & & & & & + & \\
\hline Pulmonary arterial hypertension & & & & & & & & & & & & & + & \\
\hline \multicolumn{15}{|l|}{ Gastrointestinal system } \\
\hline Osteoporosis & + & + & + & + & + & + & + & + & + & + & + & + & + & + \\
\hline \multicolumn{15}{|l|}{ Muscular system } \\
\hline Proximal limb-girdle weakness & + & + & + & + & + & + & + & + & + & + & + & + & + & + \\
\hline Bucking and dysphagia & & & & & & + & + & + & & & + & & + & \\
\hline \multicolumn{15}{|l|}{ Urinary system } \\
\hline $\begin{array}{l}\text { Lower urinary tract and sphincter } \\
\text { involvement }\end{array}$ & & & & & & & + & & & & & & + & \\
\hline
\end{tabular}

"+" represents the patient has corresponding symptom. GAA, acid alpha-glucosidase.

retesting showed GAA activity of 30.54 and $2.02 \mu \mathrm{mol} / \mathrm{L} / \mathrm{h}$, respectively. The mean serum creatine kinase level at diagnosis was $842.5 \mathrm{U} / \mathrm{L}(300-2,336 \mathrm{U} / \mathrm{L})$.

\section{Genotypes of patients}

Next-generation sequencing of the $G A A$ gene was performed in all 14 patients. In total, $17 G A A$ mutations, including 11 missense types and 6 deletion types (Figure 2, Table S1), were detected in this study. The results are summarised in Table 1 and show that c.2238G $>\mathrm{C}$ (p.W746C) was the most frequent variant, being found at an allele frequency of $14.3 \%$ (4/28). The second most frequent variants were c.1409A $>\mathrm{G}$ (p.N470S) and c. $1634 \mathrm{C}>\mathrm{T}$ (p.P545L), with an allele frequency of $10.7 \%$ (3/28). According to the Human Gene Mutation Database (HGMD), 13 out of the 17 mutations detected had been reported previously, and 4 were novel variants.
The four novel variants see Figure 2 located in exons of the $G A A$ gene included two frameshift mutations and two missense mutations. Variants c.1299G>C (p.Q443H) and c.1409A >G (p.N470S) lead to changes in highly conserved amino acids (Figure 3). Five different algorithms (Mutation t@sting, Polyphen-2, SIFT, fathmm, and MutationAssessor) were used to predict the pathogenicity of the two novel missense variants (Table 3). PyMOL software was also applied to generate the structural figures of the four novel variants and their wide types (Figure 4). The homozygous mutation c.1409A $>\mathrm{G}$ (p.N470S) in patient 2 triggered LOPD with airway infections and respiratory failure onset; in patient 7, the c.1409A>G (p.N470S) and c.2161G>T (p.E721*) mutations were responsible for the pathogenicity of the disease. The two novel frameshift variants, c.2242delG (p.E748Rfs*16) and c.2832delA (p.E945Sfs*78), also caused early termination of protein synthesis and loss of protein function after the catastrophe point. Further, 
Table 3 Evaluation of two novel missense mutations of $G A A$ gene

\begin{tabular}{|c|c|c|c|c|c|c|}
\hline DNA change & Protein change & Mutation taster & Polyphen-2 & SIFT & Fathmm & Mutation-Assesso \\
\hline c. $1409 A>G$ & p.N470s & Disease causing & $\begin{array}{l}\text { Probably damaging } \\
\text { (score: } 0.909 \text { ) }\end{array}$ & $\begin{array}{c}\text { Damaging } \\
\text { (score: } 0.034 \text { ) }\end{array}$ & $\begin{array}{c}\text { Damaging } \\
\text { (score: }-2.78 \text { ) }\end{array}$ & $\begin{array}{c}\text { Medium } \\
\text { (score: } 1.945 \text { ) }\end{array}$ \\
\hline
\end{tabular}

GAA, acid alpha-glucosidase; DNA, deoxyribonucleic acid; SIFT, sorting intolerant from tolerant.

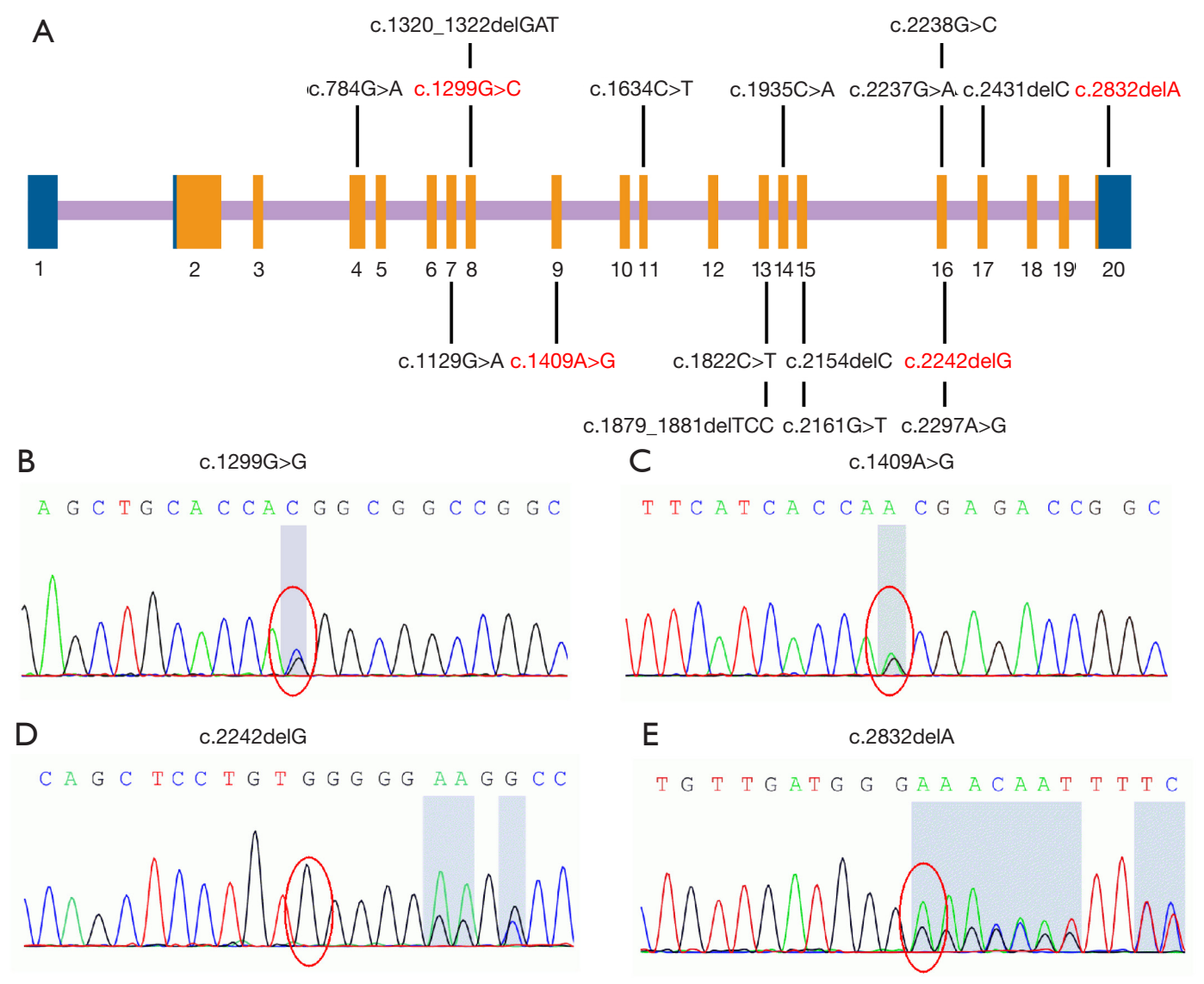

Figure 2 Seventeen $G A A$ mutations including 4 novel variants were detected. (A) Mutational spectrum of the $G A A$ gene of a cohort of 14 Chinese patients with LOPD. The novel variants are highlighted in red. (B-E) The 4 novel GAA mutations detected by next-generation sequencing: c.1299G>C (p.Q433H), c.1409A>G (p.N470S), c.2242delG (p.E748Rfs*16), and c.2832delA (p.E945Sfs*78), respectively. GAA, acid alpha-glucosidase; LOPD, late-onset Pompe disease.

according to the guidelines of American College of Medical Genetics and Genomics (ACMG) (8), the novel missense mutation c.1299G>C (p.Q433H) can be rated as a likely pathogenic variant.

\section{Course and treatment}

Patients 3 and 12 had scoliosis as the first symptom, for which they underwent posterior spinal correction surgery, and they were then diagnosed with LOPD through muscle biopsy, GAA activity testing, and $G A A$ mutation analysis. Patients 2, 5, 6, 7, 8, 9, 11, and 13 required ventilator support due to laboured breathing.

In our study, only patients 4 and 7 received ERT. Patient 4 received 18 times the full dose $(20 \mathrm{mg} / \mathrm{kg})$, but did not have regular ERT treatments in the period from September 


$\begin{array}{ll} & \text { c.1299G>C (p.Q443H) } \\ \text { Patient } & \text { PAMVQELHHGGRRYMMIVDP } \\ \text { Human } & \text { PAMVQELHQGGRRYMMIVDP } \\ \text { Mouse } & \text { PDMVRELHQDGRRYMMIVDP } \\ \text { Rat } & \text { PDMVHELHQGGRRYMMIVDP } \\ \text { Cattle } & \text { PAMVQELHQGGRRYIMIVDP } \\ \text { Zebrafish } & \text { PQMVEDFHQLGMKYVLILDP } \\ \text { Pig } & \text { PAMVRELHQGGRRYVMIVDP } \\ \text { Dog } & \text { PAMVQDLHQDGRRYVMIVDP } \\ \text { Elephant } & \text { PQMVEEFHQKGLKYVMIVDV } \\ & \\ \text { Patient } & \text { WTVDHQLLWGRPCSSPQCSR } \\ \text { Human } & \text { WTVDHQLLWGEALLITPVLQ } \\ \text { Mouse } & \text { WSVDRQLLWGPALLITPVLE } \\ \text { Rat } & \text { WSVDRQLLWGPALLITPVLE } \\ \text { Cattle } & \text { WTVDRQLLWGEALLITPVLE } \\ \text { Zebrafish } & \text { RSIDRQFLWGS SLLISPVLE } \\ \text { Pig } & \text { WTVDRQLLWGEALLVTPVLE } \\ \text { Dog } & \text { WTVDNQLLWGAAVLITPVLE } \\ \text { Elephant } & \text { LIIDRQFMWGKALLISPVLA } \\ & \end{array}$

$\begin{array}{lc} & \text { c.1409A>G (p.N470S) } \\ \text { Patient } & \text { EGLRRGVFITSETGQPLIGK } \\ \text { Human } & \text { EGLRRGVFITNETGQPLIGK } \\ \text { Mouse } & \text { EGLRRGVITNETGQPLIGK } \\ \text { Rat } & \text { EGLRRGVFITNETGQPLIGK } \\ \text { Cattle } & \text { EGLRRGVFITNETGQPLIGQ } \\ \text { Zebrafish } & \text { DGLKKGVFINNSTGQILIGK } \\ \text { Pig } & \text { EGLRRGXFVTNETGQPLIGK } \\ \text { Dog } & \text { EGLRRRVITNETGQPLIGK } \\ \text { Elephant } & \text { NGLKRGVFIKNETGQPLIGR } \\ & \\ & \text { c.2832deIA (p.E945Sfs }{ }^{*} \text { 78) } \\ \text { Patient } & \text { KVLDICVSLLMGSSFSSAGV } \\ \text { Human } & \text { KVLDICVSLLMGEQFLVSWC } \\ \text { Mouse } & \text { KSLAIPVSLLMGELFQISWS } \\ \text { Rat } & \text { KSLSIPVSLLMGERFQIDWS } \\ \text { Cattle } & \text { ETLAIPVSLTMGEQFVISWS } \\ \text { Zebrafish } & \text { KLTVAGLELPMTAKITIQWS } \\ \text { Pig } & \text { ETLDIPVSLRMGEQFLISWS } \\ \text { Dog } & \text { KTLDIPVSLMMGEQFLISWS } \\ \text { Elephant } & \text { LTLQNLSVLVGEEEFITWF }\end{array}$

Figure 3 Amino acid alignments of the four novel mutations. Variants c.1299G>C (p.Q443H) and c.1409A>G (p.N470S) lead to changes in highly conserved amino acids.

26, 2019 to December 10, 2020. Further, due to the high treatment cost and local healthcare policies, this patient has unfortunately not received ERT since December 2020. During treatment with ERT, the forced vital capacity of the patient remained unchanged. Recently, due to an increased heart rate while sleeping in a supine position, patient 4 has required intermittent non-invasive ventilation if he is positioned on his back. Patient 7 received several small doses of ERT and needed continuous non-invasive ventilation.

\section{Discussion}

Pompe disease represents a continuum of the disease spectrum. The categorization of its two subtypes is based on whether symptom onset occurs before or after 1 year of age. Typically, residual GAA activity causes LOPD to present in adulthood, presenting as proximal limbgirdle muscle weakness with prominent respiratory involvement (9). Furthermore, LOPD has broad phenotypic manifestations, including bulbar muscle involvement, scoliosis (10), osteoporosis (11), sleep apnoea and sleepdisordered breathing (12), gastrointestinal dysfunction (13), lower urinary tract and sphincter involvement, and fatigue, among others (14). The present study involved a cohort of 14 patients with LOPD from 13 families in mainland China. Proximal muscle weakness was the first prominent symptom in eight patients, while the other six patients presented with respiratory failure, chest congestion and asthma, and scoliosis, which made the LOPD difficult to diagnose. However, as the disease progressed, all patients exhibited different levels of limb-girdle muscle weakness and osteoporosis.

In our study, the median ages of the patients at symptom onset and diagnosis were 15.0 years ( $7-36$ years) and 21.5 years (8-47 years), respectively. In comparison, in a Belgian cohort (15), the mean age at symptom onset was 28.9 years [standard deviation (SD): 15.8 years]; in a French cohort (16), the mean ages at disease onset and diagnosis were 34.6 years (SD: 20.1 years) and 43.1 years (SD: 17.5 years), respectively; and in an Austrian cohort (17), the mean symptom onset age was 24.9 years (SD: 13.9 years). Therefore, one of the key findings of the present study is that the patients were younger at disease onset and diagnosis than patients in studies from other countries, which suggests racial differences in LOPD pathogenicity. This finding is also consistent with the results a previous study of 59 patients with LOPD conducted in mainland China, which reported that the mean ages at disease onset and diagnosis were 14.9 (12.35) and 22.1 (10.08) years, respectively (18).

In our study, the median diagnostic delay (from initial symptom onset to diagnosis) was 3.0 years ( $0-22$ years). However, the results reported for diagnostic delay vary considerably between countries. For instance, the diagnostic delay in cohorts from Austria, China, and Iran were 7.4, 5, and 3.3 years, respectively (17-19). Therefore, in the present study, the diagnostic delay was shorter than those previously 

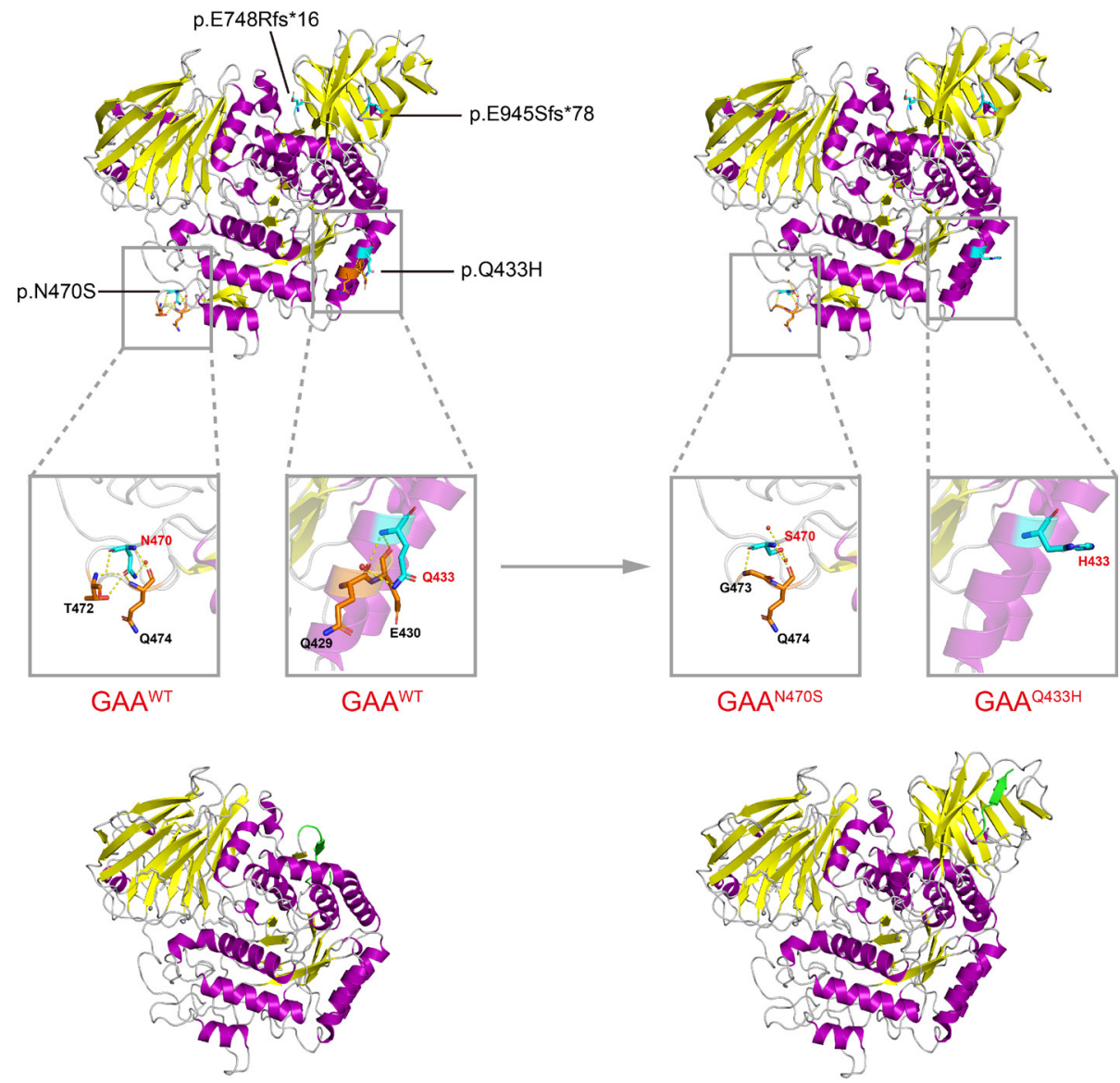

GAA $^{\text {E748Rfs*16 }}$

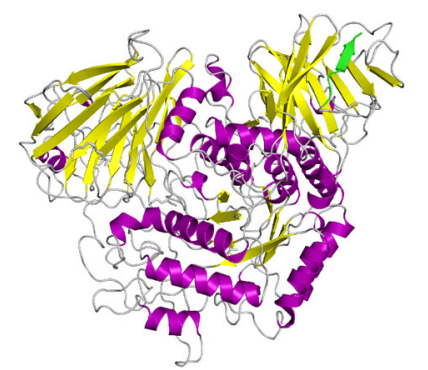

GAA $^{\text {E945Sfs*78 }}$

Figure 4 Substituted amino acids in the GAA protein. Image representation of GAA structures in its wild type (residues 79-952) and the N470S (residues 79-952), Q433H (residues 79-952), E748Rfs*16 (residues 80-760), and E945Sfs*78 (residues 80-951) mutants (PDB code: $5 \mathrm{KZW}$ ). Helices, sheets, and loops are colored purple, yellow, and grey, respectively. Residues N470 and Q433, and their mutations (S470 and H433, respectively) are shown as cyan sticks. T472/G473/Q474 and Q429/E430, which make contact with N470/Q433 and S470/ $\mathrm{H} 433$, are shown as orange sticks. Residues of the E748Rfs ${ }^{*} 16$ and E945Sfs ${ }^{\star} 8$ mutants are indicated in green. All structural figures were generated using PyMOL software (http://www.pymol.org). GAA, acid alpha-glucosidase; PDB, Protein Data Bank.

observed. The shorter diagnostic gap is likely attributable to the use of fast dried blood spot analysis or other blood analysis of GAA activity, as well as the development of genetic testing technology. It also reflects the improving awareness of Pompe disease among patients and doctors.

Intravenous ERT with recombinant human GAA is the only drug to date to address the underlying cause of Pompe disease (20). It received FDA approval to treat both IOPD and LOPD in 2007, and was approved in mainland China in 2016. The clinical response to ERT varies between patients and is associated with various factors, such as age and the degree of muscle damage at the initiation of ERT, defective autophagy, and cross-reactive immunological material
(CRIM) status. CRIM has been found to be an important predictor of clinical response in Pompe disease. CRIMnegative infantile patients usually present poorly, which is likely due to the development of a sustained high titer of neutralizing antibodies to recombinant human GAA (21). A limitation of ERT is that $20 \mathrm{mg} / \mathrm{kg}$ every week at the standard dose may be insufficient to prevent the long-term progress of the disease (22). Also, according to clinical assessments and follow-up results, a decline in pulmonary function was observed in our cohort, which is indicative of a deteriorating clinical course. However, the long-term clinical benefit of ERT remains to be demonstrated.

A total of 17 variants in the $G A A$ gene were detected 
among the 14 patients in this study, of which 4 mutations were novel and 13 mutations had been reported previously. The two novel missense variants with damaging predicted results may be novel pathogenic sites of LOPD. Genetic analysis of the 14 patients revealed that the c.2238G>C (p.W746C) mutation was found at an allele frequency of $14.3 \%(4 / 28)$ and in $28.6 \%$ of patients (4/14), making it the most frequent mutation. This mutation was previously reported in $55.56 \%$ of patients with LOPD in a mainland Chinese study, with a high allele frequency of $27.08 \%$ (23). It was also reported in $58.1 \%$ (18/31) of Pompe patients in another cohort from mainland China (18). Therefore, its frequency was comparatively low in our cohort. The novel missense variant c.1409A>G (p.N470S) was one of the second most frequently detected mutations in our cohort, with a frequency of $10.7 \%(3 / 28)$. In our study, we indicated the pathogenicity of the two novel missense variants, c.1299G G C (p.Q433H) and c.1409A>G (p.N470S), using silico data and protein modelling, but cell and animal experiments were not performed to verify their pathogenicity. Therefore, these two novel missense variants should be classified as variants of uncertain significance. Furthermore, c.2832delA (p.E945Sfs*78) occurs in the last exon of $G A A$. According to the ACMG interpretation guidelines, care should be taken in applying PVS1 as a criterion to variants in the last exon of a gene, since it is unknown if the protein will merely be truncated and still functional without having undergone nonsense-mediated decay. There is not enough evidence to support c.2832delA (p.E945Sfs ${ }^{*} 78$ ) as being pathogenic, so this variant must also be classified as a variant of uncertain significance. In future, we will carry out relevant basic research for further verification and investigation of these novel variants.

Interestingly, in patients 11 and 12 (who were brothers), who had the same mutations of the $G A A$ gene, the symptom of disease onset was different. Through careful physical examination, the brothers were found to have declined proximal and axial muscle weakness, although patient 12 was still able to walk normally. The initial symptoms of LOPD vary depending on which muscles are more affected; furthermore, environmental factors, posture and gait, mode of life, and infection may also play roles in the course of disease onset and progression.

Limitations of our study are that the study population was small and follow-up visits varied greatly without uniform assessment. In future, the genotypes and phenotypes of LOPD need larger multicentre and longer follow-up studies.

\section{Conclusions}

This study has described the genetic features and clinical manifestations of 14 mainland Chinese patients with LOPD. The result that the c.2238G>C (p.W746C) mutation in the $G A A$ gene was the most frequent mutation in our cohort is consistent with previous findings in southern Chinese patients with LOPD. This study has also identified four novel variants in patients with LOPD. These variants included c.1409A>G (p.N470S), which has not been reported before and was the second most frequent mutation among our patients; further research is required to verify the function of this mutation. Predicting the pathogenicity of these novel variants may increase the understanding of the genetic mutation spectrum of LOPD. The delay between symptom onset and diagnosis for Chinese patients with LOPD is similar to that in patients from other countries, thanks to improved detection techniques and awareness of Pompe disease in China. LOPD eventually results in wheelchair dependency and the need for a respirator, which emphasizes the necessity of prenatal diagnosis. Efforts should be made to improve awareness of the clinical and genetic characteristics of Chinese patients with LOPD among doctors and patients. However, the genotypes and phenotypes of LOPD require further research and exploration. Considering the high fatality rate of IOPD, the high disability rate of LOPD, and the high medical costs associated with the disease, prenatal diagnosis and neonatal enzymology screening are recommended.

\section{Acknowledgments}

We thank the study participants and their families for their involvement in this study, and for permitting their data to be used for scientific research.

Funding: This work was financially supported by the National Natural Science Foundation of China (No. 82071434), the Natural Science Foundation of Jiangsu (No. BK20201490), Nanjing Medical University Specific Disease Cohort Study Project (No. NMUC2019007A), Jiangsu Province "Six Talent Peak" High-Level Talent Selection and Training Programme (No. WSN-004), and the 511 Project.

\section{Footnote}

Reporting Checklist: The authors have completed the 
MDAR reporting checklist. Available at https://dx.doi. org/10.21037/atm-21-3710

Data Sharing Statement: Available at https://dx.doi. org/10.21037/atm-21-3710

Peer Review File: Available at https://dx.doi.org/10.21037/ atm-21-3710

Conflicts of Interest: All authors have completed the ICMJE uniform disclosure form (available at https://dx.doi. org/10.21037/atm-21-3710). The authors have no conflicts of interest to declare.

Ethical Statement: The authors are accountable for all aspects of the work in ensuring that questions related to the accuracy or integrity of any part of the work are appropriately investigated and resolved. The study was conducted in accordance with the Declaration of Helsinki (as revised in 2013). The study was approved by the Medical Ethics Review Board of The First Affiliated Hospital of Nanjing Medical University (2021-SR-415). The patients and their families gave informed consent for the use of their medical data for research purposes.

Open Access Statement: This is an Open Access article distributed in accordance with the Creative Commons Attribution-NonCommercial-NoDerivs 4.0 International License (CC BY-NC-ND 4.0), which permits the noncommercial replication and distribution of the article with the strict proviso that no changes or edits are made and the original work is properly cited (including links to both the formal publication through the relevant DOI and the license). See: https://creativecommons.org/licenses/by-nc-nd/4.0/.

\section{References}

1. Chen X, Liu T, Huang M, et al. Clinical and Molecular Characterization of Infantile-Onset Pompe Disease in Mainland Chinese Patients: Identification of Two Common Mutations. Genet Test Mol Biomarkers 2017;21:391-6.

2. Lim JA, Li L, Raben N. Pompe disease: from pathophysiology to therapy and back again. Front Aging Neurosci 2014;6:177.

3. Su X, Sheng H, Huang Y, et al. Clinical and GAA gene mutation analysis in 21 Chinese patients with classic infantile pompe disease. Eur J Med Genet 2020;63:103997.
4. Tarnopolsky M, Katzberg H, Petrof BJ, et al. Pompe Disease: Diagnosis and Management. Evidence-Based Guidelines from a Canadian Expert Panel. Can J Neurol Sci 2016;43:472-85.

5. Hoefsloot LH, Hoogeveen-Westerveld M, Reuser AJ, et al. Characterization of the human lysosomal alphaglucosidase gene. Biochem J 1990;272:493-7.

6. Buratti E, Peruzzo P, Braga L, et al. Deferoxamine mesylate improves splicing and GAA activity of the common c.-32-13 $\mathrm{T}>\mathrm{G}$ allele in late-onset $\mathrm{PD}$ patient fibroblasts. Mol Ther Methods Clin Dev 2021;20:227-36.

7. Yang CC, Chien YH, Lee NC, et al. Rapid progressive course of later-onset Pompe disease in Chinese patients. Mol Genet Metab 2011;104:284-8.

8. Richards S, Aziz N, Bale S, et al. Standards and guidelines for the interpretation of sequence variants: a joint consensus recommendation of the American College of Medical Genetics and Genomics and the Association for Molecular Pathology. Genet Med 2015;17:405-24.

9. van der Ploeg AT, Reuser AJ. Pompe's disease. Lancet 2008;372:1342-53.

10. Haaker G, Forst J, Forst R, et al. Orthopedic management of patients with Pompe disease: a retrospective case series of 8 patients. ScientificWorldJournal 2014;2014:963861.

11. Horvath JJ, Austin SL, Case LE, et al. Correlation between quantitative whole-body muscle magnetic resonance imaging and clinical muscle weakness in Pompe disease. Muscle Nerve 2015;51:722-30.

12. Boentert M, Karabul N, Wenninger S, et al. Sleep-related symptoms and sleep-disordered breathing in adult Pompe disease. Eur J Neurol 2015;22:369-76, e27.

13. Bernstein DL, Bialer MG, Mehta L, et al. Pompe disease: dramatic improvement in gastrointestinal function following enzyme replacement therapy. A report of three later-onset patients. Mol Genet Metab 2010;101:130-3.

14. Chan J, Desai AK, Kazi ZB, et al. The emerging phenotype of late-onset Pompe disease: A systematic literature review. Mol Genet Metab 2017;120:163-72.

15. Vanherpe P, Fieuws S, D'Hondt A, et al. Late-onset Pompe disease (LOPD) in Belgium: clinical characteristics and outcome measures. Orphanet J Rare Dis 2020;15:83.

16. Semplicini C, Letard P, De Antonio M, et al. Lateonset Pompe disease in France: molecular features and epidemiology from a nationwide study. J Inherit Metab Dis 2018;41:937-46.

17. Löscher WN, Huemer M, Stulnig TM, et al. Pompe disease in Austria: clinical, genetic and epidemiological aspects. J Neurol 2018;265:159-64. 
18. Zhao Y, Wang Z, Lu J, et al. Characteristics of Pompe disease in China: a report from the Pompe registry. Orphanet J Rare Dis 2019;14:78.

19. Nazari F, Sinaei F, Nilipour Y, et al. Late-onset Pompe disease in Iran, a clinical and genetic report. Muscle Nerve 2017;55:835-40.

20. Hahn A, Schänzer A. Long-term outcome and unmet needs in infantile-onset Pompe disease. Ann Transl Med 2019;7:283.

21. Bali DS, Goldstein JL, Banugaria S, et al. Predicting crossreactive immunological material (CRIM) status in Pompe disease using GAA mutations: lessons learned from 10 years of clinical laboratory testing experience. Am J Med

Cite this article as: Zhao $\mathrm{HH}, \mathrm{Ma} \mathrm{Z}$, Ying $\mathrm{ZX}$, Niu FN, Luo MT, Wang Z, Cheng X, Zhang QQ, Niu Q. Clinical manifestations and acid alpha-glucosidase mutation characterisation of a cohort of patients with late-onset Pompe disease in eastern China. Ann Transl Med 2021;9(24):1803. doi: 10.21037/atm-21-3710
Genet C Semin Med Genet 2012;160C:40-9.

22. Khan AA, Case LE, Herbert M, et al. Higher dosing of alglucosidase alfa improves outcomes in children with Pompe disease: a clinical study and review of the literature. Genet Med 2020;22:898-907.

23. Liu X, Wang Z, Jin W, et al. Clinical and GAA gene mutation analysis in mainland Chinese patients with lateonset Pompe disease: identifying c.2238G > C as the most common mutation. BMC Med Genet 2014;15:141.

(English Language Editors: Chelsea Mullens and J. Reynolds) 
Supplementary

Table S1 Genetic analysis of 14 Chinese patients with late-onset Pompe disease and pedigree validation

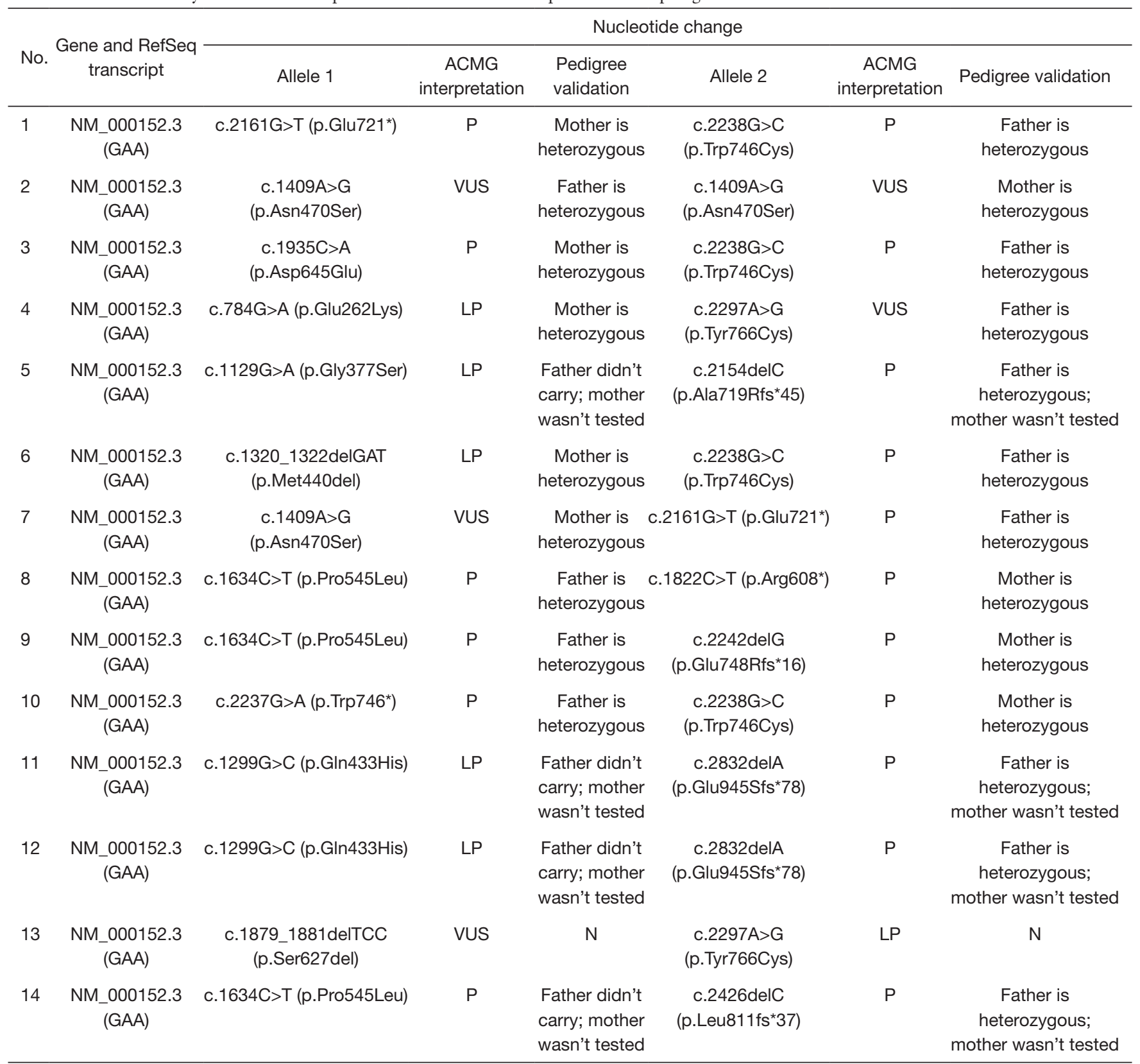

ACMG, American College of Medical Genetics and Genomics; GAA, acid alpha-glucosidase; P, pathogenic; LP, likely pathogenic; VUS, uncertain significance; N, unknown. 